\title{
IL-17 aggravates renal injury by promoting podocyte injury in children with primary nephrotic syndrome
}

\author{
SHUBO ZHAI, BAICHAO SUN, YAN ZHANG, LENGYUE ZHAO and LI ZHANG
}

Department of Pediatric Nephrology, The First Hospital of Jilin University, Changchun, Jilin 130021, P.R. China

Received November 7, 2018; Accepted September 26, 2019

DOI: $10.3892 /$ etm.2020.8698

\begin{abstract}
Primary nephrotic syndrome (PNS) is the most common chronic kidney disease in childhood, where podocyte injury is a key factor in the occurrence of kidney disease. In the present study, the expression of IL-17 in renal tissues of patients with PNS and its relationship with podocyte injury were examined. Reverse transcription-quantitative PCR (RT-qPCR), western blot analysis and immunochemistry were used to measure the expression of IL-17 in renal biopsies of patients with ONS, including 9 patients with minimal change nephrotic syndrome (MCNS), 15 patients with mesangial proliferative glomerulonephritis (MsPGN) and 9 patients with focal segmental glomerulosclerosis (FSGS), in addition to 15 normal kidney tissues. IL-17 was found to be highly expressed in the renal tissues from patients with PNS, with the highest expression levels found in tissues from patients with FSGS and the lowest in those from MCNS. A negative correlation was observed between the levels of IL-17 mRNA and PCX mRNA in renal tissues, whereas a positive correlation between IL-17 mRNA levels and the number of urinary podocytes in patients with PNS was found. In vitro, IL-17 induced podocyte apoptosis and reduced the expression of markers associated with podocytes, including Wilm's tumor 1, nephrin, synaptopodin and podocalyxin, whilst increasing the levels of Fas, Fas ligand (FasL), active-caspase-8, active-caspase-3 and phosphorylated-p65. However, treatment with helenalin, a NF- $\kappa$ B inhibitor, decreased p 65 phosphorylation, attenuated IL-17-induced podocyte apoptosis and suppressed the IL-17-activated Fas/FasL/caspase-8/caspase-3 apoptotic pathway. Taken together, these observations suggest that IL-17 was highly expressed in renal tissues from patients with PNS, where it induced podocyte apoptosis by activating the Fas/FasL/caspase-8/caspase-3 apoptotic pathway in a $\mathrm{NF}-\kappa \mathrm{B}$-dependent manner.
\end{abstract}

Correspondence to: Professor Li Zhang, Department of Pediatric Nephrology, The First Hospital of Jilin University, 71 Xin Min Street, Jilin, Changchun, Jilin 130021, P.R. China

E-mail: zhanglifhju@163.com

Key words: interleukin-17, primary nephrotic syndrome, podocyte, children

\section{Introduction}

Primary nephrotic syndrome (PNS) is the most common chronic kidney disease in children and is also the main cause of chronic renal failure in adults in China $(1,2)$. Previous studies have found that the cause of chronic kidney diseases in adults originates from PNS during childhood, which can be alleviated by treatment $(3,4)$. The etiology and pathogenesis of childhood PNS remain unclear. However, it is well-documented that proteinuria, hypoproteinemia, hyperlipidemia and edema are the main pathophysiological characteristics associated with PNS, with proteinuria being the core change $(2,5)$. Damage to the glomerular filtration barrier is the direct cause of proteinuria, where the abnormal number or function of podocytes are a cause of pathological changes in glomerular filtration membrane permeability, proteinuria formation and ultimately glomerular sclerosis $(6,7)$. Podocyte injuries have been reported to participate in the formation of urinary fistula and glomerular sclerosis, such that signs of podocyte injury have been observed in the urine of patients with primary and secondary glomerular disease $(8,9)$. Additionally, previous studies have found that a variety of factors, including anti-capsular antibodies, metabolic factors, hemodynamics and infection, can result in podocyte damage $(10,11)$.

Interleukin (IL)-17 is a proinflammatory cytokine secreted by Th17 cells (12) that promotes the secretion of IL-1 $\beta$, tumor necrosis factor (TNF)- $\alpha$ and IL- 6 by binding to their corresponding receptors mainly expressed in the epithelial and endothelial cells of the kidney and spleen (13-15). Previous studies have found that the IL-23/IL-17 pathway contributes significantly to renal tissue injury in experimental glomerulonephritis (16) and patients with PNS (17), where the inhibition of IL-17 expression in patients with renal disease attenuated crescent formation in nephrotoxic serum nephritis (18). However, it currently remains unclear whether IL-17 can influence the development of PNS by regulating podocyte injury.

In the present study, the relationship between IL-17 and PNS, specifically that between IL-17 and inflammatory podocyte injury, were investigated. It was found that IL-17 was highly expressed in renal tissues of patients with PNS and was associated with indicators of podocyte injury. In addition, IL-17 induced podocyte apoptosis by activating the Fas/Fas ligand (FasL)/caspase-8/caspase-3 apoptotic pathway via $\mathrm{NF}-\kappa \mathrm{B}$ activation in vitro. In conclusion, data from the 
present study provided a potential target for attenuating podocyte injury in children with PNS by suppressing inflammation.

\section{Materials and methods}

Tissues and ethics statement. Renal biopsies of 9 patients with minimal change nephrotic syndrome (MCNS) (3 female and 6 males; mean age, $8.6 \pm 2.3$ years), 15 patients with mesangial proliferative glomerulonephritis (MsPGN) (6 females and 9 males; mean age, $8.2 \pm 2.4$ years) and 9 patients with focal segmental glomerulosclerosis (FSGS) (3 females and 6 males; mean age, $8.4 \pm 2.8$ years) were collected at The First Hospital of Jilin University (Changchun, China) from January 2015 to December 2017. In addition, normal kidney tissues were collected from 15 patients ( 6 females and 9 males, age range, 3-10 years, mean age, 8.5 \pm 3.0 years) at The First Hospital of Jilin University (Jilin, China) during early renal tumor surgery; normal routine urine test results and renal function were observed. The inclusion criteria used were as follows: i) All PNS patients were diagnosed according to the diagnostic criteria for glomerular nephropathy in China (19); ii) patients with PNS were $<10$ years of age and did not receive any medication prior to renal puncture; iii) the patients with PNS has complete clinical data, including age and sex data. The exclusion criteria were as follows: i) Other organ tissue dysfunction; ii) Infected with HIV, HCV or tuberculosis; iii) had received surgical treatment within half a year; iv) exhibited epilepsy, congenital heart disease or any other genetic diseases. All relevant guardians or patients of the participants in the present study provided signed informed consent and the experiments were approved by the Ethics Association of The First Hospital of Jilin University (Changchun, China). No animals were used in the present study.

Cell lines and drugs. Podocytes (20,21), from H-2Kb-tsA58 transgenic mice, were a gift from Professor Peter Mundel (Mount Sinai School of Medicine, New York University, USA) and were cultured at $37^{\circ} \mathrm{C}$ with $5 \% \mathrm{CO}_{2}$ in DMEM (cat. no. 12491-15; Thermo Fisher Scientific, Inc.) supplemented with $10 \%$ fetal bovine serum (cat. no. 10100-147; Thermo Fisher Scientific, Inc.) and 1\% penicillin/streptomycin (cat. no. 1564005; Thermo Fisher Scientific, Inc.).

A total of $1.5 \times 10^{6}$ cells/well of podocytes were seeded into six-well plates and were treated with $0,50,100$ and $200 \mathrm{ng} / \mathrm{ml}$ recombinant mouse IL-17 (rmIL-17; cat. no. PMC0175; Thermo Fisher Scientific, Inc.) for 24,48 or $72 \mathrm{~h}$. A total of $5 \mu \mathrm{M}$ helenalin (cat. no. 6754-13-8; Cayman Chemical Company) was added to podocytes with $200 \mathrm{ng} / \mathrm{ml} \mathrm{rmIL-17} \mathrm{for} 72 \mathrm{~h}$. Cell culture supernatant was collected using centrifugation $\left(2,000 \mathrm{x} \mathrm{g} ; 10 \mathrm{~min} ; 4^{\circ} \mathrm{C}\right)$, and the concentration of IL-1 $\beta$ in the cell culture supernatant was subsequently measured using the IL-1 $\beta$ mouse uncoated ELISA kit (cat. no. 88-7013-88; Thermo Fisher Scientific, Inc.) and TNF- $\alpha$ was measured using the TNF- $\alpha$ mouse ELISA kit (cat. no. BMS607-3; Thermo Fisher Scientific, Inc.).

Reverse transcription-quantitative PCR (RT-qPCR). TRIzol ${ }^{\mathrm{B}}$ (cat. no. 15596018; Thermo Fisher Scientific, Inc.) was used to extract total RNA from kidney tissues or cells. The extracted RNA was then reverse transcribed into cDNA by using PrimeScript ${ }^{\mathrm{TH}}$ RT Master Mix (cat. no. RR036B; Takara Biotechnology Co., Ltd.), with the temperature protocol of $37^{\circ} \mathrm{C}$ for $60 \mathrm{~min}$ and $85^{\circ} \mathrm{C}$ for $5 \mathrm{sec}$. Subsequently, $20 \mu \mathrm{l}$ fluorescence quantitative PCR (qPCR) reactions were prepared according to the manufacturer's protocol of the SYBR ${ }^{\circledR}$-Green qPCR Master Mix (cat. no. 638320; Takara Biotechnology Co., Ltd.) and amplified using ABI 7500 Real-Time PCR System (Applied Biosystems; Thermo Fisher Scientific, Inc.). The following thermocycling conditions were used: Initial denaturation at $95^{\circ} \mathrm{C}$ for $30 \mathrm{sec}$, followed by 40 cycles of $90^{\circ} \mathrm{C}$ for $5 \mathrm{sec}$ and $65^{\circ} \mathrm{C}$ for $30 \mathrm{sec}$. Sequences of all primers used for RT-qPCR analysis are provided in Table I. We used the $2^{-\Delta \Delta C q}$ method (22) to calculate the relative expression levels of genes, and GAPDH was used for normalization.

Western blotting. Tissues and cells were submerged in RIPA lysate (cat. no. P0013C; Beyotime Institute of Biotechnology), and detected protein concentration using a BCA kit (cat. no. P0012; Beyotime Institute of Biotechnology), and a total of $40 \mu \mathrm{g}$ protein were separated by 5\% SDS-PAGE and then transferred to PVDF membranes. BSA (5\%) which was 5\% BSA buffer solution (cat. no. ST-023; Beyotime Institute of Biotechnology) in PBS as a blocking solution to block for $1 \mathrm{~h}$ at room temperature, and then washed 3 times with PBS buffer. Membranes were subsequently incubated with primary antibodies against IL-17 (cat. no. sc-374218; 1:500; Santa Cruz Biotechnology, Inc.), Fas (cat. no. ab82419; 1:1,000; Abcam), FasL (cat. no. ab15285; 1:1,000; Abcam), active caspase-8 (cat. no. ab227430; 1:2,000; Abcam), active caspase-3 (cat. no. ab49822; 1:500; Abcam), p65 phosphorylated (p-) S636 (cat. no. ab86299; 1:5,000) or GAPDH (cat. no. ab9484; 1:3,000) overnight at $4^{\circ} \mathrm{C}$, followed by incubation with Goat Anti-Rabbit IgG H\&L (HRP) (cat. no. ab6721; 1:1,000) or Goat Anti-Mouse IgG H\&L (HRP) (cat. no. ab205719; 1:1,000) secondary antibodies for $1 \mathrm{~h}$ at room temperature, and then ECL solution (cat. no. WBKLS0100, Beijing Xinjingke Biotechnologies Co., Ltd.) was added for detection. Protein expression levels were analyzed using ImageJ v1.8.0 (National Institutes of Health), with the calculated gray scale values of target proteins/GAPDH used to quantify relative expression.

Immunohistochemistry. IL-17 protein expression was detected by immunohistochemical staining according to the protocol of the VECTASTAIN ${ }^{\circledast}$ Elite $^{\circledR}$ ABC Kit (Vector Laboratories, Inc.; Maravai LifeSciences) in the kidney tissue sections. The $5 \mu \mathrm{m}$ paraffin sections were incubated at $60^{\circ} \mathrm{C}$ for $2 \mathrm{~h}$ after soaking in $3 \%$ hydrogen peroxide solution, dewaxed and hydrated using xylene and an ethanol gradient, following which sections were washed with PBS and double distilled water. 5\% BSA which was 5\% BSA buffer solution in PBS as a blocking solution to block for $1 \mathrm{~h}$ at room temperature. The sections were subsequently stained using an anti-IL-17 primary antibody (1:100; cat. no. sc-374218; Santa Cruz Biotechnologies, Inc.) or PBS (negative control) overnight at $4^{\circ} \mathrm{C}$, followed by incubation with horseradish peroxidase-conjugated goat anti-rabbit IgG H\&L secondary antibodies (cat. no. ab6721; 1:500; Abcam) at $37^{\circ} \mathrm{C}$ for $2 \mathrm{~h}$. Finally, DAB staining (cat. no. P0203; Beyotime Institute of Biotechnology) for $10 \mathrm{~min}$ at room temperature and hematoxylin staining at room temperature (cat. no. C0107; 
Table I. Sequences of primers used for reverse transcription-quantitative PCR.

\begin{tabular}{ll}
\hline Gene & \multicolumn{1}{c}{ Primer sequence (5'-3') } \\
\hline IL-17 & F: TCCCACGAAATCCAGGATGC \\
& R: GGATGTTCAGGTTGACCATCAC \\
Podocalyxin & F: TCCCAGAATGCAACCCAGAC \\
(human) & R: GGTGAGTCACTGGATACACCAA \\
Podocalyxin & F: AGTGCCACAACATCAACAGAA \\
(murine) & R: TGTGAATGGTGTAGGGTTGCT \\
WT1 & F: AGCACGGTCACTTTCGACG \\
& R: GTTTGAAGGAATGGTTGGGAA \\
Nephrin & F: ATGGGAGCTAAGGAAGCCACA \\
& R: CCACACCACAGCTTAACTGTC \\
Synaptopodin & F: TCCTCACCTAATGCCACACTC \\
& R: GCTGGAGGGTTTGGTTGATA \\
GAPDH (human) & F: ACAACTTTGGTATCGTGGAAGG \\
& R: GCCATCACGCCACAGTTC \\
GAPDH (murine) & F: AGGTCGGTGTGAACGGATTTG \\
& R: GGGGTCGTTGATGGCAACA
\end{tabular}

IL-17, interleukin 17; WT1, Wilm's tumor 1; F, forward; R, reverse. next day, the slides were rinsed three times with PBS supplemented with $0.05 \%$ Tween-20 (PBS-T), following which Goat Anti-Rabbit IgG H\&L (Alexa Fluor ${ }^{\circledR}$ 488; cat. no. ab150077; 1:1,000; Abcam) was added and the slides were incubated in a wet box at $20-37^{\circ} \mathrm{C}$ for $1 \mathrm{~h}$. A concentration of $5 \mu \mathrm{g} / \mathrm{ml}$ DAPI (cat. no. 4083; Cell Signaling Technology, Inc.) was subsequently added before the slides were incubated in the dark for $5 \mathrm{~min}$ at room temperature to stain the nuclei of the specimen. Following the removal of excess DAPI by rinsing with PBS-T (4x5 min), the slides were dried using absorbent paper and an anti-fluorescence quenching sealant (cat. no. HCY078; Hangzhou Yuxin Biotechnology Co., Ltd.) was used. A fluorescence microscope was then used to acquire images. Counting the average of urinary podocytes were counted from 10 high-powered (magnification, x200) fields of view.

Flow cytometric analysis of apoptosis. Total of $2-3 \times 10^{6}$ cells/well of podocytes were collected following treatment for 24, 48 and $72 \mathrm{~h}$ with 0, 50, 100 and $200 \mathrm{ng} / \mathrm{ml} \mathrm{IL-7} \mathrm{and}$ the Annexin V-FITC/propidium iodide kit (cat. no. V13241; Invitrogen; Thermo Fisher Scientific, Inc.) was used to detect apoptosis according to manufacturer's protocol. Beckman CytoFLEX Flow cytometer (Beckman Coulter, Inc.) with Flowjo 10.0 software (Beckman Coulter, Inc.) was used to analyze podocyte apoptosis.

Statistical analysis. Data are presented as the mean \pm standard deviation from three independent repetitions per experiment and were analyzed using SPSS 20.0 (IBM Corp.). Unpaired Student's t-test was used to compare differences between two groups, whilst comparison between multiple groups was performed using the One-way ANOVA followed by Duncan's tests. Correlation between two groups was analyzed by Pearson's correlation analysis. $\mathrm{P}<0.05$ was considered to indicate a statistically significant difference.

\section{Results}

IL-17 is highly expressed in patients with PNS. RT-qPCR was used to measure the expression of IL-17 mRNA, whereas western blotting and immunohistochemistry were performed for IL-17 protein expression in patient tissue samples. The expression of IL-17 in renal tissues of patients with PNS was found to be significantly higher compared with that of normal kidney tissues (Fig. 1A and B). In addition, the expression level of IL-17 also appeared to associate with disease severity in patients with PNS (Fig. 1C), as IL-17 expression was found to be highest in renal tissues of patients with FSGS ( $n=9)$ and lowest in MCNS $(n=9)$. Taken together, IL-17 was highly expressed in the renal tissues of patients with PNS and was associated with the severity of PNS in patients.

IL-17 is associated with podocyte injury in patients with PNS. Podocalyxin (PCX) is a podocyte-specific marker protein (24). Podocytes in the urine are derived from podocytes shed from kidney tissue (25) and PCX levels can be related to podocyte injury. The expression of PCX mRNA in kidney tissue of patients with PNS was measured using RT-qPCR and the
[EPR9518] (cat. no. ab150358; 1:1,000; Abcam) was added into slides and incubated in a wet box overnight at $4^{\circ} \mathrm{C}$. The 

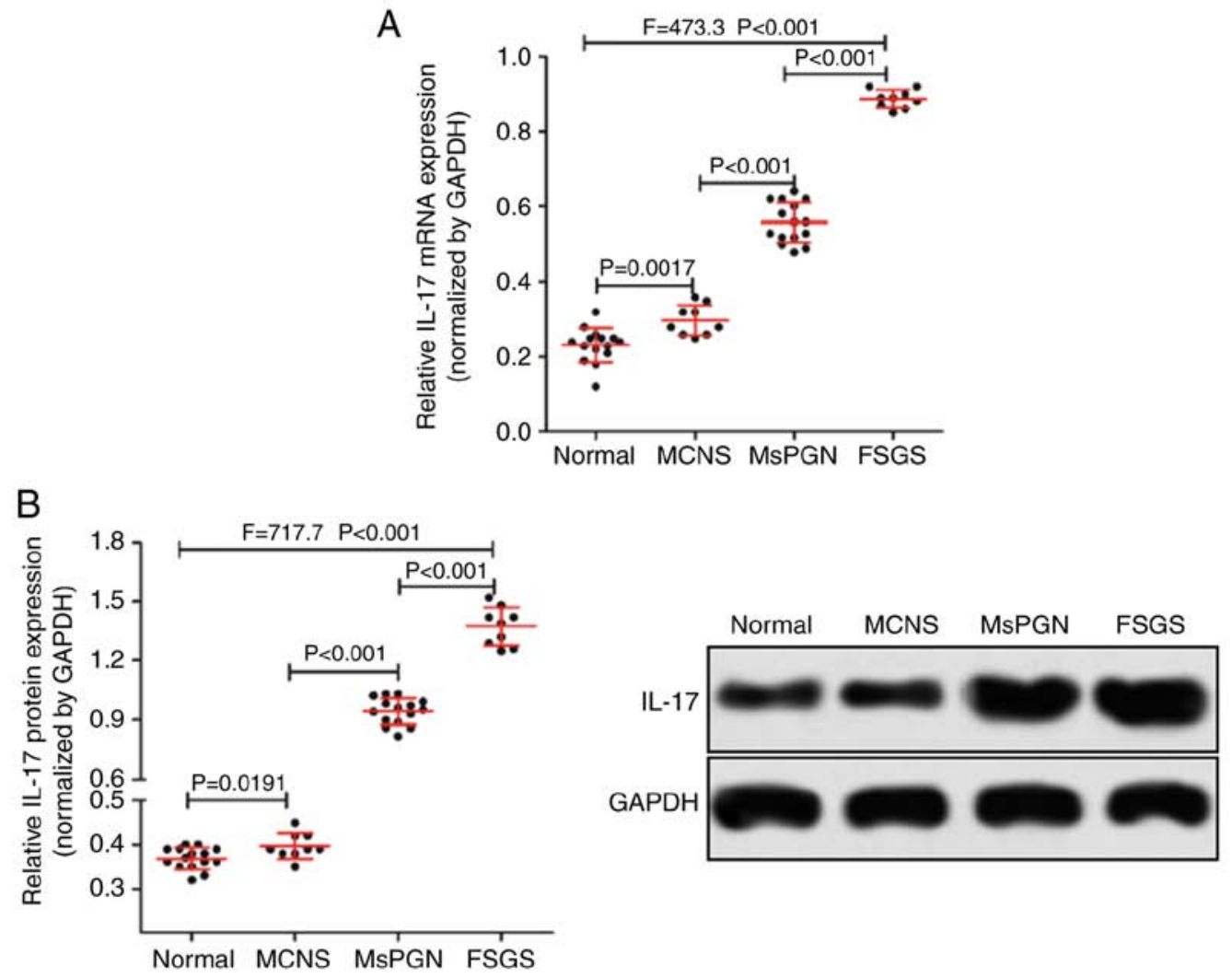

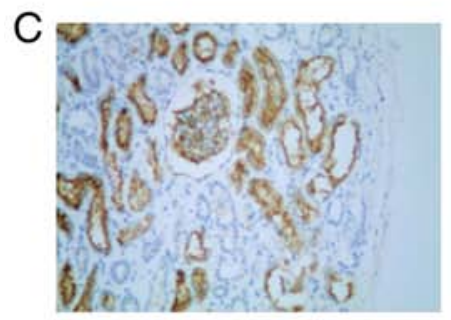

Normal

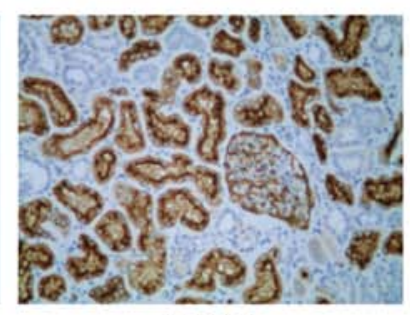

MCNS

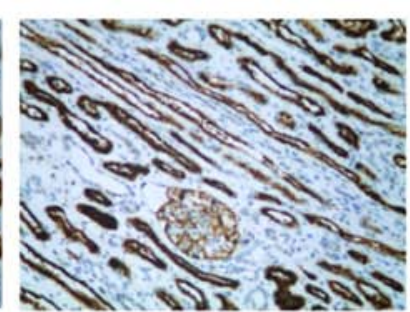

MSPGN

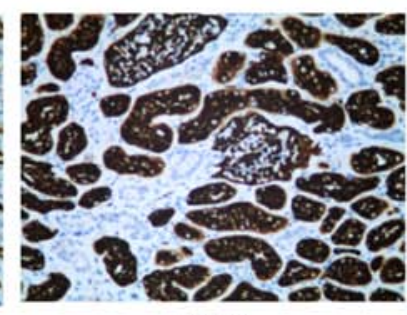

FSGS

Figure 1. Comparison of IL-17 expression in kidney tissues from patients with and without PNS. (A) Reverse transcription-quantitative PCR was performed to detect the expression of IL-17 mRNA. (B) Western blotting was performed to measure the expression of IL-17 protein in the kidney tissues of patients without PNS ( $n=15)$, with MCNS ( $n=9)$, MsPGN ( $n=15)$ or FSGS ( $n=9)$. (C) Representative images of immunohistochemical staining displaying IL-17 protein expression in kidney tissues from the four groups of patients (magnification, x200). IL-17, interleukin-17; PNS, primary nephrotic syndrome; MCNS, minimal change nephrotic syndrome; MsPGN, mesangial proliferative glomerulonephritis; FSGS, focal segmental glomerulosclerosis.

number of podocytes (MCNS was $1.67 \pm 0.38$, MsPGN was $7.06 \pm 0.72$, FSGS was $10.44 \pm 0.69$ ) was counted using immunofluorescence detection of PCX proteins (Fig. 2A and C). It was found that there was a negative correlation between IL-17 and PCX mRNA expression in the renal tissue (Fig. 2B), whilst a positive correlation was found between IL-17 mRNA expression and the number of urinary podocytes in patients with PNS (Fig. 2D). The results suggest that the expression of IL-17 was correlated with podocyte injury in patients with PNS.

IL-17 induces podocyte apoptosis in vitro. Flow cytometry was used to measure apoptosis in podocytes following the addition of ascending concentrations $(0,50,100$ and $200 \mathrm{ng} / \mathrm{ml})$ of rmIL-17 to the culture medium. After 24,48 and $72 \mathrm{~h}$ treatment, podocytes were collected for analysis of apoptosis and gene expression. For each dose of rmIL-17, the apoptotic rate of podocytes increased with increasing culture time (Fig. 3A). Furthermore, at each time point the apoptotic rate of podocytes increased as the rmIL-17 dose increased (Fig. 3A). These observations suggested that IL-17 induced podocyte apoptosis in vitro in a time- and dose-dependent manner.

According to the experimental results obtained in Fig. 3A, a dose of $200 \mathrm{ng} / \mathrm{ml} \mathrm{rmIL-17} \mathrm{for} \mathrm{a} \mathrm{treatment} \mathrm{of} 72 \mathrm{~h}$ was chosen for subsequent experiments. The mRNA expression of podocyte marker molecules, WT1, nephrin, synaptopodin and podocalyxin were significantly reduced following IL-17 treatment (Fig. 3B). In addition, IL-17 treatment increased the expression of Fas, FasL, active-caspase- 8 and active-caspase- 3 proteins (Fig. 4). These results suggested that IL-17 induced podocyte apoptosis by activating the Fas/FasL/caspase-8/caspase-3 signaling pathway in podocytes in vitro.

IL-17 activates the $N F-\kappa B$ signaling pathway in podocytes in vitro. The phosphorylation of $\mathrm{p} 65$ subunit of $\mathrm{NF}-\kappa \mathrm{B}$ was increased following IL-17 treatment (Fig. 4), suggesting that the $\mathrm{NF}-\kappa \mathrm{B}$ pathway was activated (26). Since this signaling pathway controls the transcription of a plethora of genes associated with inflammation (27), the hypothesis that IL-17 

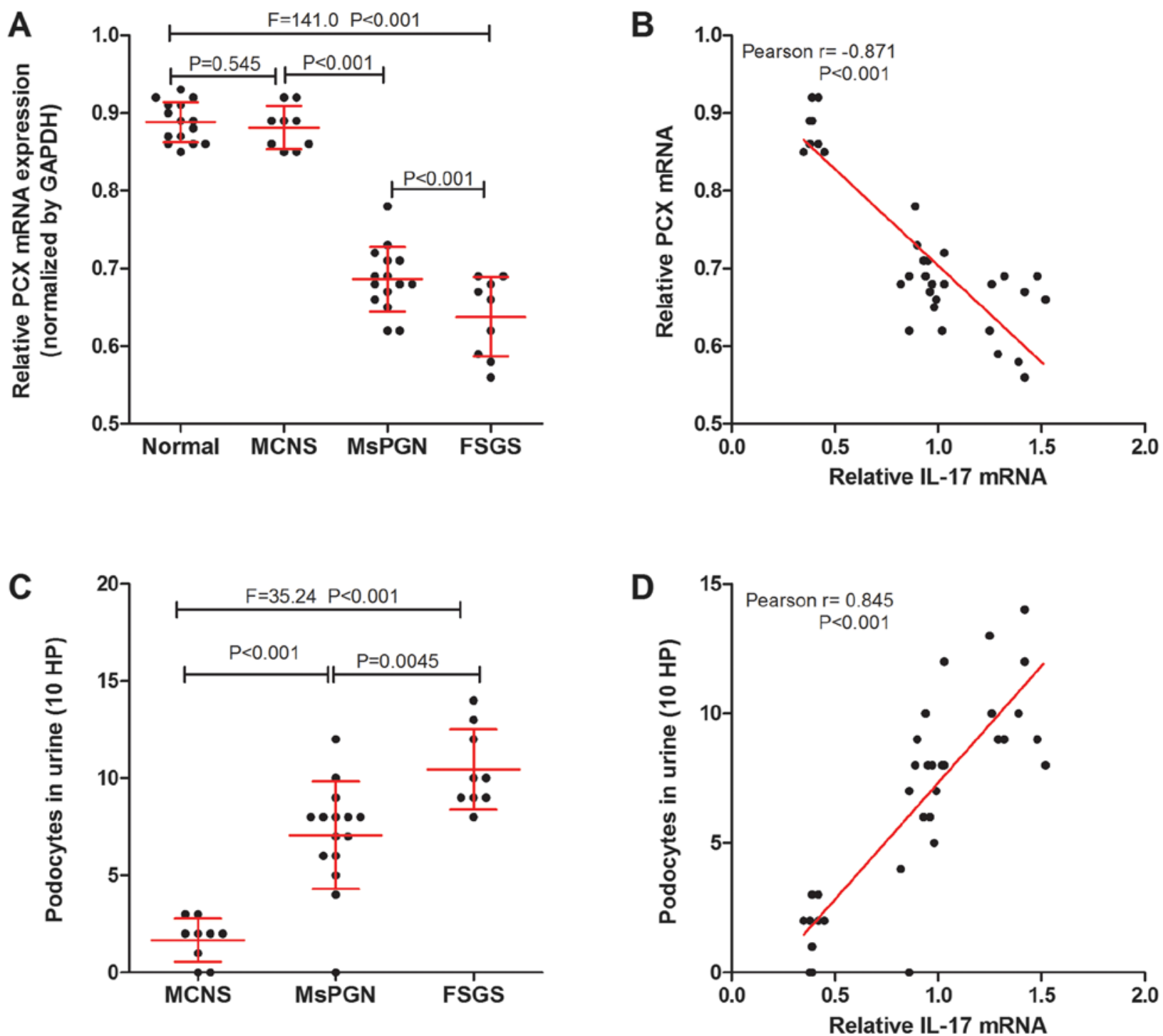

Figure 2. IL-17 is associated with podocyte injury markers in patients with PNS. (A) Reverse transcription-quantitative PCR was performed to measure the expression of PCX mRNA in the kidney tissues of normal patients without PNS ( $n=15)$, and of patients with MCNS ( $n=9)$, MsPGN ( $n=15)$ and FSGS ( $n=9)$. (B) IL-17 mRNA was negatively correlated with PCX mRNA expression in the kidney tissues of PNS patients $(\mathrm{n}=33)$. (C) The number of urinary podocytes in patients with MCNS ( $\mathrm{n}=9$ ), MsPGN ( $\mathrm{n}=15)$ and FSGS $(\mathrm{n}=9)$. (D) A positive correlation was observed between the levels of IL-17 mRNA in renal tissues and the number of urinary podocytes in patients with PNS $(\mathrm{n}=33)$. IL-17, interleukin-17; PNS, primary nephrotic syndrome; MCNS, minimal change nephrotic syndrome; MsPGN, mesangial proliferative glomerulonephritis; FSGS, focal segmental glomerulosclerosis; PCX, podocalyxin; HP, high power fields.

induced podocyte apoptosis by upregulating inflammation was first tested, by measuring the levels IL-1 $\beta$ and TNF- $\alpha$ content in the podocyte culture supernatant following IL-17 treatment. IL-17 treatment increased the secretion of IL-1 $\beta$ and TNF- $\alpha$ in a time- and dose-dependent manner (Fig. 5A and B). To investigate the relationship between IL-17-induced podocyte apoptosis, IL-1 $\beta$ and TNF- $\alpha$ secretion and the NF- $\mathrm{B}$ pathway, podocytes were treated with helenalin, a NF- $\mathrm{B}$ inhibitor, in the presence of IL-17. Helenalin significantly attenuated IL-17-induced podocyte apoptosis (Fig. 5C), and IL-1 $\beta$ (Fig. 5D) and TNF- $\alpha$ (Fig. 5E) secretion by podocytes. Additionally, helenalin also significantly inhibited IL-17-activated NF- $\kappa$ B signaling via p65 phosphorylation and the Fas/FasL/caspase-8/caspase-3 apoptotic pathway (Fig. 4). These results suggested that IL-17-induced podocyte apoptosis may be associated with the NF- $\mathrm{KB}$ signaling pathway.

\section{Discussion}

Over the past two decades, studies have found that among children with PNS, the incidence of FSGS has exhibited an increasing trend, seriously affecting the prognosis of patients with PNS $(28,29)$. However, development of treatment strategies for PNS is hindered by the poorly understood mechanism of glomerular sclerosis pathogenesis. It has been previously reported that inflammation mediated by $\mathrm{CD} 4^{+} \mathrm{T}$ cell dysfunction is associated with the occurrence of glomerular sclerosis $(30,31)$. Traditionally, $\mathrm{CD}^{+} \mathrm{T}$ cells are divided into Th1 and Th2 subtypes. Th1 cells are mainly associated with the secretion of cytokines IL- 2 and IFN- $\gamma$, which mediate cellular immune responses, whereas Th2 mainly secrete cytokines IL-4 and IL-10, which mediate fluid immune responses $(32,33)$. Although some studies have demonstrated that the dysfunction of Th1/Th2 and the dominant activation of Th2 serve an 

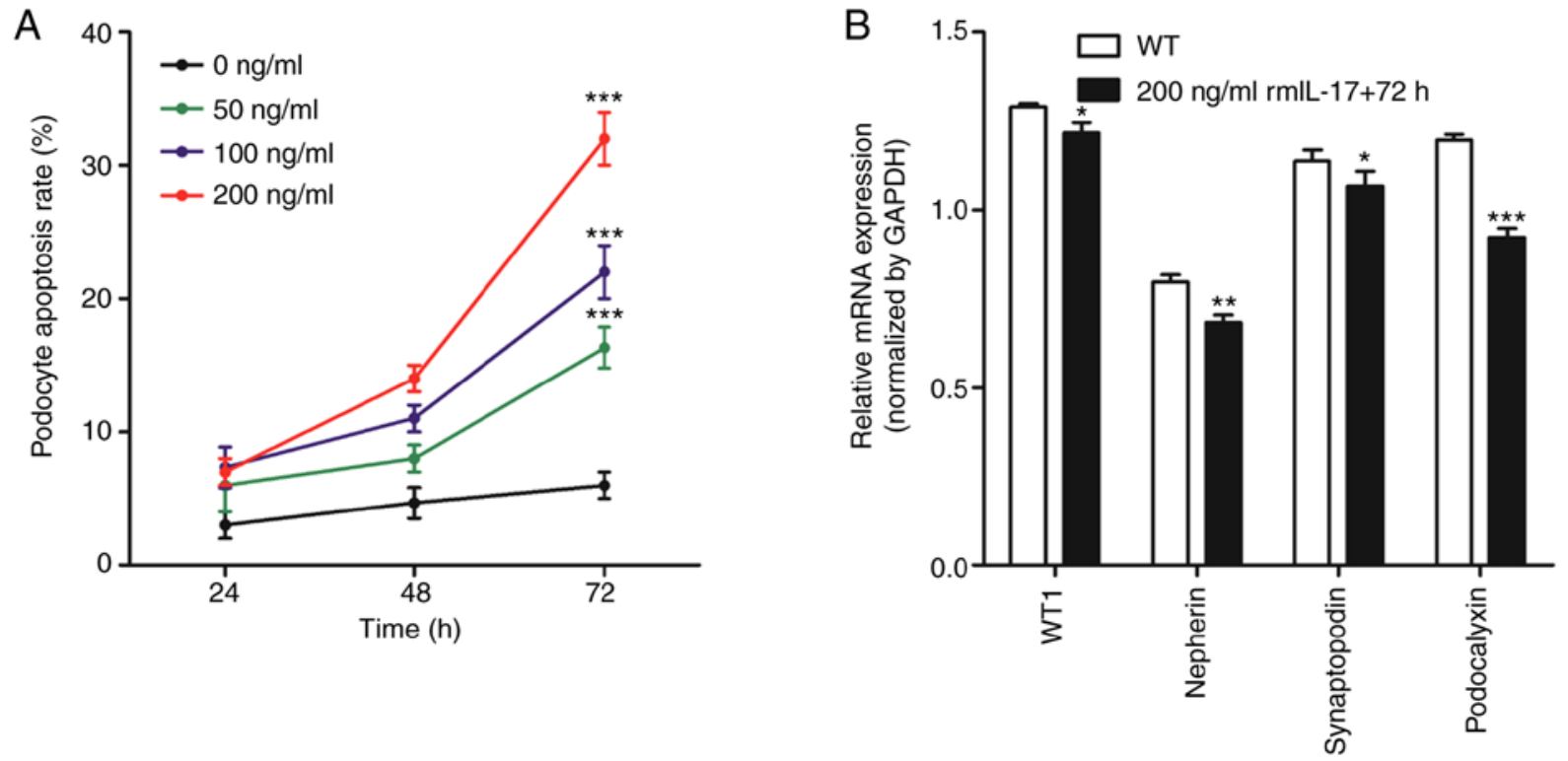

Figure 3. IL-17 induces podocyte apoptosis and affects the expression of podocyte markers in vitro. (A) IL-17 induced podocyte apoptosis in vitro in a timeand dose-dependent manner, based on flow cytometric analysis. ${ }^{* * *} \mathrm{P}<0.001 \mathrm{vs.} 0 \mathrm{ng} / \mathrm{ml}$. (B) Reverse transcription-quantitative PCR was performed to measure mRNA expression of WT1, nephrin, synaptopodin and podocalyxin. ${ }^{*} \mathrm{P}<0.05,{ }^{* *} \mathrm{P}<0.01$ and $^{* * * *} \mathrm{P}<0.001 \mathrm{vs}$. WT group. Data are presented as the mean \pm standard deviation from three independent repetitions per experiment. WT, wild-type; WT1, Wilm's tumor 1; IL-17, interleukin-17; rmIL-17, recombinant mouse IL-17.

important role in the development of kidney disease $(34,35)$; however, other studies have opposing views $(36,37)$. Therefore, the balance of Th1/Th2 activation alone is not sufficient to fully explain the mechanism of glomerular sclerosis pathogenesis.

In recent years, Th17 cells were discovered as additional $\mathrm{CD}^{+} \mathrm{T}$ cells, which have a different mechanism of differentiation, but phenotypes and functions are derived from Th1/Th2 (38). IL-17 is an important cytokine secreted by Th17 cells, which has been found to associate closely with the development of coronary heart disease $(39,40)$, multiple sclerosis (41), inflammation and autoimmune diseases (15). In kidney diseases, Matsumoto et al (42) found that the excretion of IL-17 in urine during the minimally active period was significantly higher compared with that in the remission period, which was in turn proportional to the excretion of urinary protein. In addition, IL-17 was also found to be associated with renal tissue injury in experimental glomerulonephritis (16), patients with PNS (17) and the severity of IgA nephropathy (43). In the present study, it was found that the expression of IL-17 in the renal tissues of patients with PNS was significantly higher compared with that of normal kidney tissues, which was also associated with the severity of disease in patients with PNS. In addition, it was found that IL-17 expression was associated with indicators of podocyte injury.

Podocytes damage is a signature of nephrotic syndrome $(44,45)$. Podocytes are glomerular visceral epithelial cells, which belong to a class of terminally differentiated cells. When podocytes are damaged, the normal structure of the foot processes is destroyed, resulting in podocytes detaching from the basement membrane. Since this cannot be repaired effectively due to the limited proliferative ability of podocytes (44), the integrity of the glomerular filtration membrane is compromised, leading to proteinuria. In the present study, it was found in vitro that IL-17 treatment induced podocyte apoptosis in addition to reducing the mRNA expression of podocyte-specific markers, including WT1, nephrin, synaptopodin and podocalyxin. Indeed, expression of these markers were directly associated with podocyte integrity, where studies have found that the loss or mutation of podocalyxin leads to the development of FSGS and familial nephrotic syndrome $(46,47)$. Additionally, Fluvastatin treatment, which is mainly used to treat primary hypercholesterolemia and primary mixed dyslipidemia, protects podocytes in HIV-associated nephropathy by increasing the expression of nephrin, WT1 and synaptopodin $(48,49)$.

To explore the molecular mechanism by which IL-17 induces podocyte apoptosis further, changes in protein expression in cultured podocytes following IL-17 treatment were examined. IL-17 treatment increased the expression of Fas, FasL, active-caspase-8, active-caspase- 3 in addition to p65 phosphorylation, all of which were reversed by concomitant treatment with the $\mathrm{NF}-\kappa \mathrm{B}$ inhibitor helenalin. A previous study has shown that inflammatory factors can induce muscle cell apoptosis by activating the Fas/FasL-caspase-8-caspase-3 pathway (50). NF- $\kappa \mathrm{B}$ signaling controls the transcription of a variety of genes associated with inflammation, including IL- $1 \beta$ and TNF- $\alpha$, which in turn can potentiate NF- $\kappa$ B signaling further (51). Therefore, it is possible that IL-17 first increased the secretion of IL- $1 \beta$ and TNF- $\alpha$ by activating the $\mathrm{NF}-\kappa \mathrm{B}$ pathway in podocytes, where these inflammatory factors increased podocyte apoptosis of by activating the Fas/FasL-caspase-8-caspase-3 pathway.

However, it should be emphasized that some limitations exist for the present study. The podocytes used in the in vitro study were cell lines and not primary cells. Secondly, the sample size of the tissues collected from each disease group were small. In addition, inhibitors for the related signaling pathways mentioned in the present study were not used.

In conclusion, results from the present study suggested that IL-17 was highly expressed in renal tissues of patients with 

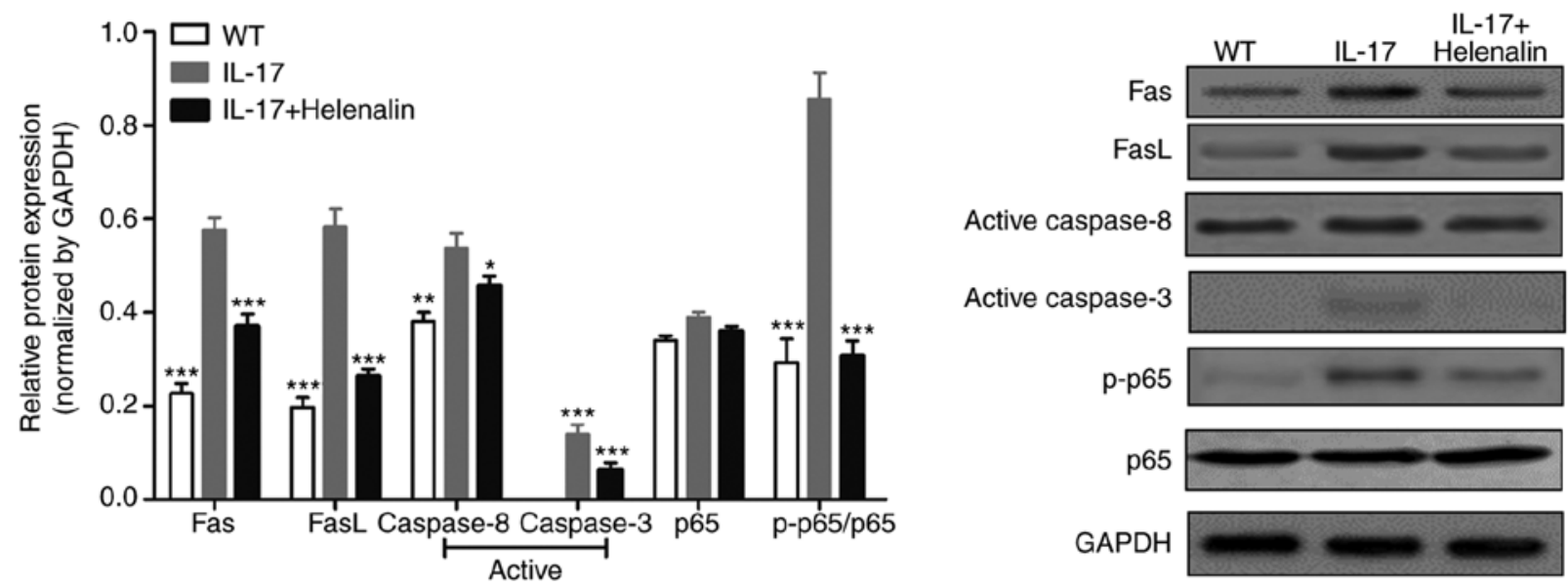

Figure 4. IL-17 activates the NF- $\mathrm{BB}$ and Fas/FasL/caspase-8/caspase-3 signaling pathways in podocytes in vitro. Western blot analysis was performed to measure the protein levels of Fas, FasL, active-caspase-8, active-caspase-3, p65 and p-p65 in cultured podocytes following IL-17 and/or helenalin treatment. Data are presented as the mean \pm standard deviation from three independent repetitions per experiment. ${ }^{*} \mathrm{P}<0.05,{ }^{* *} \mathrm{P}<0.01$ and ${ }^{* * * *} \mathrm{P}<0.001$ vs. IL-17. FasL, Fas ligand; p-, phosphorylated.
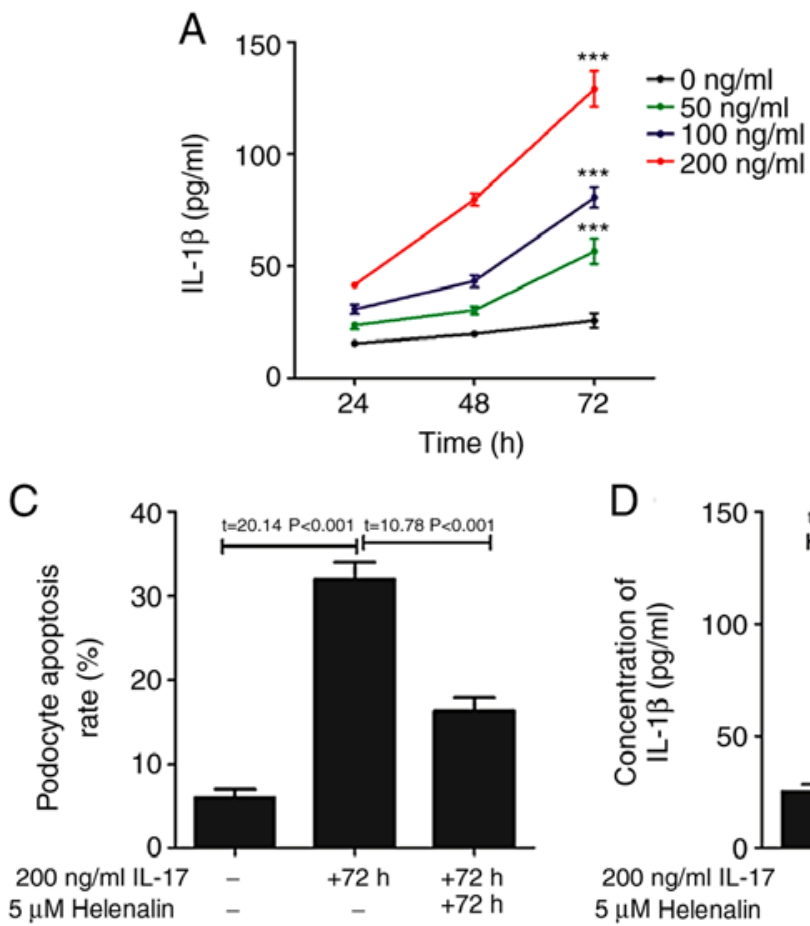
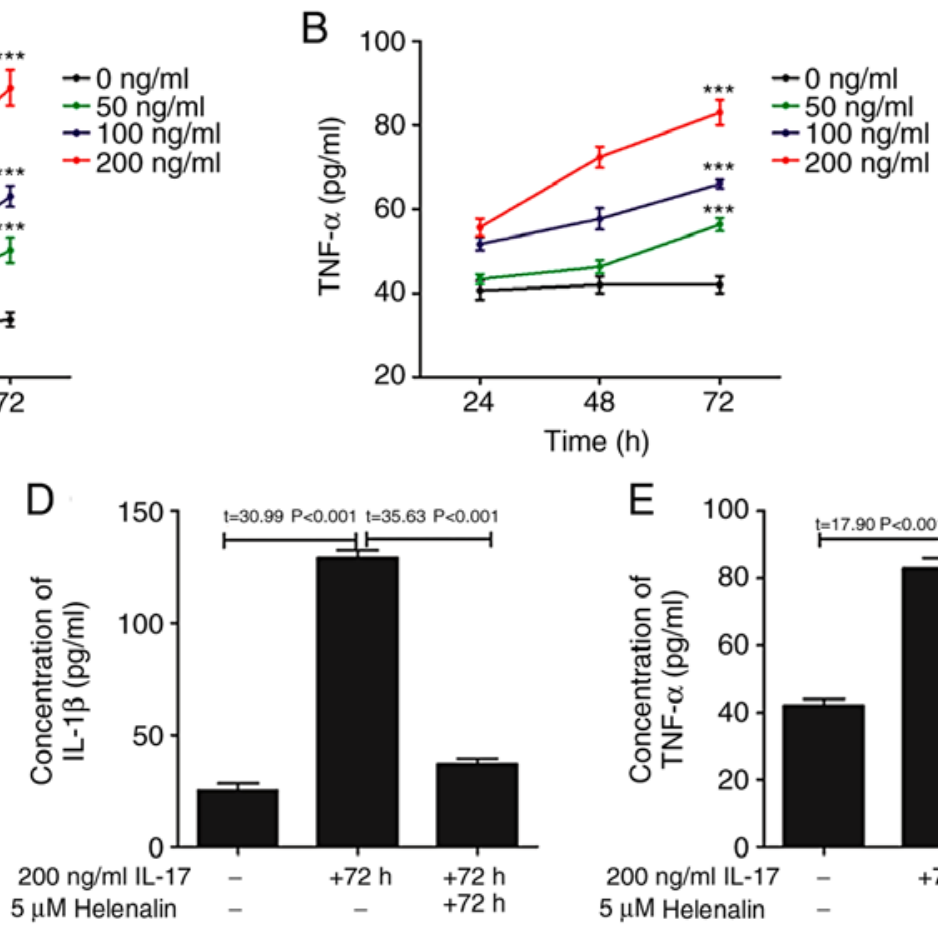

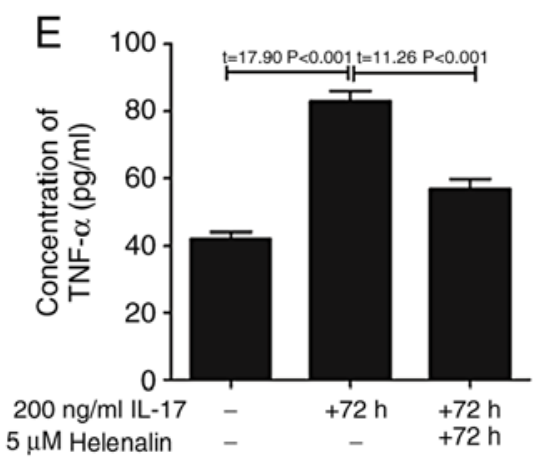

Figure 5. NF- $\mathrm{BB}$ inhibition by helenalin attenuates IL-17-induced podocyte apoptosis and secretion of IL-1 $\beta$ or TNF- $\alpha$ by podocytes. IL-17 induced the secretion of (A) IL- $1 \beta$ and (B) TNF- $\alpha$ in vitro in a time- and dose-dependent manner. ${ }^{* * * *} \mathrm{P}<0.001 \mathrm{vs} .0 \mathrm{ng} / \mathrm{ml}$. (C) NF- $\mathrm{KB}$ inhibitor helenalin attenuated IL-17-induced podocyte apoptosis. Helenalin attenuated IL-17-induced the secretion of (D) IL-1 $\beta$ and (E) TNF- $\alpha$. Data are presented as the mean \pm standard deviation from three independent repetitions per experiment. IL, interleukin; TNF- $\alpha$, tumor necrosis factor- $\alpha$.

PNS. The Fas/FasL/caspase-8/caspase-3 apoptotic pathway was activated in a NF- $\mathrm{KB}-$ dependent manner to induce podocyte apoptosis.

\section{Acknowledgements}

Not applicable.

\section{Funding}

No funding was received.

\section{Availability of data and materials}

All data generated or analyzed during the present study are included in this published article.

\section{Authors' contributions}

LZ was responsible for the conception and design of the study; SZ prepared the manuscript and revised the final draft of the manuscript; SZ, BS, YZ and LYZ performed the experiments and analyzed the data. 


\section{Ethics approval and consent to participate}

The present study was performed with the approval of the Ethics Committee of The First Hospital of Jilin University. All aspects of the study complied with the Declaration of Helsinki. All relevant guardians or parents of patients provided written informed consent.

\section{Patient consent for publication}

Not applicable.

\section{Competing interests}

The authors declare that they have no competing interests.

\section{References}

1. Trautmann A, Schnaidt S, Lipska-Ziettkiewicz BS, Bodria M, Ozaltin F, Emma F, Anarat A, Melk A, Azocar M, Oh J, et al: Long-term outcome of steroid-resistant nephrotic syndrome in children. J Am Soc Nephrol 28: 3055-3065, 2017.

2. Kopp JB: Global glomerulosclerosis in primary nephrotic syndrome: Including age as a variable to predict renal outcomes. Kidney Int 93: 1043-1044, 2018.

3. Levey AS, Eckardt KU, Tsukamoto Y, Levin A, Coresh J, Rossert J, De Zeeuw D, Hostetter TH, Lameire N and Eknoyan G: Definition and classification of chronic kidney disease: A position statement from kidney disease: Improving Global Outcomes (KDIGO). Kidney Int 67: 2089-2100, 2005.

4. Levey AS, Andreoli SP, Dubose T, Provenzano R and Collins AJ: Chronic kidney disease: Common, harmful and treatable-World Kidney Day 2007. Am J Nephrol 27: 108-112, 2007.

5. Bennett MR: Biomarkers of therapeutic response in primary nephrotic syndrome: Response. Pediat Nephrol 28: 161-162, 2013.

6. Chen W, Jiang Y, Han J, Hu J, He T, Yan T, Huang N, Zhang Q, Mei $\mathrm{H}$, Liao Y, et al: Atgl deficiency induces podocyte apoptosis and leads to glomerular filtration barrier damage. FEBS J 284: 1070-1081, 2017.

7. Tian X, Kim JJ, Monkley SM, Gotoh N, Nandez R, Soda K, Inoue K, Balkin DM, Hassan H,Son SH, et al: Podocyte-associated talin1 is critical for glomerular filtration barrier maintenance. J Clin Invest 124: 1098-1113, 2014.

8. Petermann A and Floege J: Podocyte damage resulting in podocyturia: A potential diagnostic marker to assess glomerular disease activity. Nephron Clin Pract 106: c61-c66, 2007.

9. Perico L, Conti S, Benigni A and Remuzzi G: Podocyte-actin dynamics in health and disease. Nat Rev Nephrol 12: 692, 2016.

10. Nagata M: Podocyte injury and its consequences. Kidney Int 89: 1221-1230, 2016.

11. Ivanova EA, Arcolino FO, Elmonem MA, Rastaldi MP, Giardino L, Cornelissen EM, Van Den Heuvel LP and Levtchenko EN: Cystinosin deficiency causes podocyte damage and loss associated with increased cell motility. Kidney Int 89: 1037-1048, 2016.

12. Korn T, Bettelli E, Oukka M and Kuchroo VK: IL-17 and Th17 cells. Annu Rev Immunol 8: 485-517, 2009.

13. Beringer A, Noack M and Miossec P: IL-17 in chronic inflammation: From discovery to targeting. Trends Mol Med 22: 230-241, 2016.

14. Ivanov II, Mckenzie BS, Zhou L, Tadokoro CE, Lepelley A, Lafaille JJ, Cua DJ and Littman DR: The orphan nuclear receptor RORgammat directs the differentiation program of proinflammatory IL-17+ $\mathrm{T}$ helper cells. Cell 126: 1121-1133, 2006.

15. Kuwabara T, Ishikawa F, Kondo $M$ and Kakiuchi T: The role of IL-17 and related cytokines in inflammatory autoimmune diseases. Mediators Inflamm 2017: 3908061, 2017.

16. Paust HJ, Turner JE, Steinmetz OM, Peters A, Heymann F, Hölscher C, Wolf G, Kurts C, Mittrücker HW, Stahl RA and Panzer U: The IL-23/Th17 axis contributes to renal injury in experimental glomerulonephritis. J Am Soc Nephrol 20: 969, 2009.
17. Zhang L, Yan J, Yang B, Zhang G, Wang M, Dong S, Liu W, Yang $H$ and Li Q: IL-23 actived $\gamma \delta$ T cells affect Th17 cells and regulatory $\mathrm{T}$ cells by secreting IL-21 in children with primary nephrotic syndrome. Scand J Immunol 87: 36, 2017.

18. Okada H, Inoue T, Hashimoto K, Suzuki H and Matsushita S: D1-like receptor antagonist inhibits IL-17 expression and attenuates crescent formation in nephrotoxic serum nephritis. Am J Nephrol 30: 274-279, 2009.

19. Jennette JC and Falk RJ: Diagnosis and management of glomerular diseases. Med Clin North Am 81: 653-677, 1997.

20. Ji Z, Hu Z and Xu Y: APPL1 acts as a protective factor against podocytes injury in high glucose environment. Int J Clin Exp Pathol 8: 6764-6771, 2015.

21. Rops AL, van der Vlag J, Jacobs CW, Dijkman HB, Lensen JF, Wijnhoven TJ, van den Heuvel LP, van Kuppevelt TH and Berden JH: Isolation and characterization of conditionally immortalized mouse glomerular endothelial cell lines. Kidney Int 66: 2193-2201, 2004.

22. Livak KJ and Schmittgen TD: Analysis of relative gene expression data using real-time quantitative PCR and the 2(-Delta Delta C(T)) method. Methods 25: 402-408, 2001.

23. Zhang YM, You LF, Chen J and Mao CP: Expression of kinesin family member $3 \mathrm{~B}$ is associated with poor prognosis in epithelial ovarian cancer patients. Int J Clin Exp Pathol 10: 2834-2842, 2017.

24. Chen WQ, Zhang Y, Jiang H, Li H, Li XY, Yang X, Feng S, Wang YC, Lin C, Shen XJ, et al: Podocyte-related proteins in membranous nephropathy progression. Chinese J Med (Engl) 126: 3782-3783, 2013.

25. Yu D, Petermann A, Kunter U, Rong S, Shankland SJ and Floege J: Urinary podocyte loss is a more specific marker of ongoing glomerular damage than proteinuria. J Am Soc Nephrol 16: 1733-1741, 2005.

26. Buss H, Dörrie A, Schmitz ML, Hoffmann E, Resch K and Kracht M: Constitutive and interleukin-1-inducible phosphorylation of p65 NF- $\{$ kappa $\} \mathrm{B}$ at serine 536 is mediated by multiple protein kinases including I\{kappa\}B kinase (IKK)-\{alpha\}, IKK $\{$ beta\}, IKK $\{$ epsilon\}, TRAF family member-associated (TANK)-binding kinase 1 (TBK1), and an unknown kinase and couples p65 to TATA-binding protein-associated factor II31-mediated interleukin-8 transcription. J Biol Chem 279: 55633-55643, 2004.

27. Monaco C, Andreakos E, Kiriakidis S, Mauri C, Bicknell C, Foxwell B, Cheshire N, Paleolog E and Feldmann M: Canonical pathway of nuclear factor $\kappa \mathrm{B}$ activation selectively regulates proinflammatory and prothrombotic responses in human atherosclerosis. Proc Natl Acad Sci USA 101: 5634-5639, 2004.

28. Yin XL, Zou MS, Zhang Y, Wang J, Liu TL, Tang JH, Qiu LR, Chen Y, Yuan HQ and Zhou JH: Twenty-three-year review of disease patterns from renal biopsies: An experience from a pediatric renal center. J Nephrol 26: 699-707, 2013.

29. Yuen LK, Lai WM, Lau SC, Tong PC, Tse KC and Chiu MC: Ten-year review of disease pattern from percutaneous renal biopsy: An experience from a paediatric tertiary renal centre in Hong Kong. Hong Kong Med J 14: 348-355, 2008.

30. Umemoto S, Okamoto T, Yoshimura K, Sakumura T, Murata T, Fukai T, Yano M and Matsuzaki M: Toll-like receptor 4 function is essential for increasing oxidative stress, and promoting the inflammation and glomerular sclerosis by angiotensin II. J Am Coll Cardiol 67: 2243-2243, 2016.

31. Reggiani F and Ponticelli C: Focal segmental glomerular sclerosis: Do not overlook the role of immune response. J Nephrol 29: 525-534, 2016.

32. Cousins DJ, Lee TH and Staynov DZ: Cytokine coexpression during human Th1/Th2 cell differentiation: Direct evidence for coordinated expression of Th2 cytokines. J Immunol 169: 2498-2506, 2002.

33. Egwuagu CE, Yu CR, Zhang M, Mahdi RM, Kim SJ and Gery I: Suppressors of cytokine signaling proteins are differentially expressed in Th1 and Th2 cells: Implications for Th cell lineage commitment and maintenance. J Immunol 168: 3181-3187, 2002

34. Essa S, Pacsa A, Raghupathy R, Said T, Nampoory MRN, Johny KV and Alnakib W: Low levels of Th1-type cytokines and increased levels of Th2-type cytokines in kidney transplant recipients with active cytomegalovirus infection. Transplant Proc 41: 1643-1647, 2009.

35. Hwang YJ, Yun MO, Jeong KT and Park JH: Uremic toxin indoxyl 3-sulfate regulates the differentiation of Th2 but not of Th1 cells to lessen allergic asthma. Toxicol Lett 225: 130-138, 2014. 
36. Lama G, Luongo I, Tirino G, Borriello A, Carangio C and Salsano ME: T-lymphocyte populations and cytokines in childhood nephrotic syndrome. Am J Kidney Dis 39: 958-965, 2002.

37. Kaneko K, Tuchiya K, Fujinaga S, Kawamura R, Ohtomo Y, Shimizu T and Yamashiro Y: Th1/Th2 balance in childhood idiopathic nephrotic syndrome. Clin Nephrol 58: 393-397, 2002.

38. Weaver CT, Harrington LE, Mangan PR, Gavrieli M and Murphy KM: Th17: An effector CD4 T cell lineage with regulatory T cell ties. Immunity 24: 677-688, 2006.

39. Gong F, Liu Z, Liu J, Zhou P, Liu Y and Lu X: The paradoxical role of IL-17 in atherosclerosis. Cell Immunol 297: 33-39, 2015.

40. Potekhina AV, Pylaeva E, Provatorov S, Ruleva N, Masenko V, Noeva E, Krasnikova T and Arefieva T: Treg/Th17 balance in stable CAD patients with different stages of coronary atherosclerosis. Atherosclerosis 238: 17-21, 2015.

41. Babaloo Z, Aliparasti MR, Babaiea F, Almasi S, Baradaran B and Farhoudi M: The role of Th17 cells in patients with relapsing-remitting multiple sclerosis: Interleukin-17A and interleukin-17F serum levels. Immunol Lett 164: 76-80, 2015.

42. Matsumoto K and Kanmatsuse K: Increased urinary excretion of interleukin-17 in nephrotic patients. Nephron 91: 243-249, 2002.

43. Matsumoto $\mathrm{K}$ and Kanmatsuse K: Interleukin-17 stimulates the release of pro-inflammatory cytokines by blood monocytes in patients with IgA nephropathy. Scand J Urol Nephrol 37: 164-171, 2003.

44. Niranjan T, Bielesz B, Gruenwald A, Ponda MP, Kopp JB, Thomas DB and Susztak K: The Notch pathway in podocytes plays a role in the development of glomerular disease. Nat Med 14: 290, 2008.

45. Reiser J, von Gersdorff G, Loos M, Oh J, Asanuma K, Giardino L, Rastaldi MP, Calvaresi N, Watanabe H, Schwarz K, et al: Induction of B7-1 in podocytes is associated with nephrotic syndrome. J Clin Invest 113: 1390-1397, 2004.
46. Kavoura E, Gakiopoulou H, Paraskevakou H, Marinaki S, Agrogiannis G, Stofas A, Boletis I, Patsouris E and Lazaris AC: Immunohistochemical evaluation of podocalyxin expression in glomerulopathies associated with nephrotic syndrome. Hum Pathol 42: 227-235, 2011.

47. Mollet G, Ratelade J, Boyer O, Muda AO, Morisset L, Lavin TA, Kitzis D, Dallman MJ, Bugeon L, Hubner N, et al: Podocin inactivation in mature kidneys causes focal segmental glomerulosclerosis and nephrotic syndrome. J Am Soc Nephrol 20: 2181-2189, 2009.

48. Sakurai N Kuroiwa T, Ikeuchi H, Hiramatsu N, Takeuchi S, Tomioka M, Shigehara T, Maeshima A, Kaneko Y and Hiromura K: Fluvastatin prevents podocyte injury in a murine model of HIV-associated nephropathy. Nephrol Dial Transplant 24: 2378-2383, 2009

49. Wei P, Grimm PR, Settles DC, Balwanz CR, Padanilam BJ and Sansom SC: Simvastatin reverses podocyte injury but not mesangial expansion in early stage type 2 diabetes mellitus. Ren Fail 31: 503-513, 2009

50. Kondo M, Murakawa Y, Harashima N, Kobayashi S, Yamaguchi S and Harada M: Roles of proinflammatory cytokines and the Fas/Fas ligand interaction in the pathogenesis of inflammatory myopathies. Immunology 128 (Suppl 1): e589-e599, 2009.

51. Sun SC: The non-canonical NF- $\mathrm{KB}$ pathway in immunity and inflammation. Nat Rev Immunol 17: 545-558, 2017. International (CC BY-NC-ND 4.0) License. 